\title{
Percutaneous Approach in Pneumology
}

\author{
P.L. Aliprandi1, F.P. Basile1, G.F. Tassi2
}

Monaldi Arch Chest Dis 2011; 75: 1, 95-98.

Keywords: Chest drainage, Transthoracic fine needle aspiration, Radiofrequency ablation, Pleural disease, Lung Cancer.

1 U.O. Medicina III, Pneumologia Interventistica, Ospedale di Rho, A.O.G. Salvini, Garbagnate Milanese (Milano),

2 U.O. Pneumologia, Spedali Civili, Brescia, Italy.

Correspondence: Dr. P.L. Aliprandi, U.O. Medicina III, Pneumologia Interventistica, Ospedale di Rho, A.O.G. Salvini, Garbagnate Milanese, Corso Europa 250, 20024 Rho (Milano), Italy; e-mail: paliprandi@aogarbagnate.lombardia.it

\section{Thoracic drainage}

Chest drainage is an essential tool in the treatment of pneumothorax (PNX), spontaneous or post-traumatic, of pleural empyema, haemotorax, chylothorax, recurrent pleural effusion that is not responding to pleurodesis and, finally, after thoracoscopy or thoracic surgery (both traditional and video assisted) (Level of evidence: IV) (Grade C) [1-5].

In cases of PNX, observational approach is largely sufficient and needle aspiration can have decisive results. Drainage should always be placed in ventilated patients, if the PNX is bilateral, hypertensive, recurrent after fine needle aspiration or in the extensive secondary PNX ( $>2 \mathrm{cms})$. The "large" size of PNX (presence of a visible rim of more than $2 \mathrm{~cm}$ between the lung margin and the chest wall at the level of the hilum) is a relative indication for active intervention (Level of evidence: IV) (Grade C) [2, 3, 4, 6].

The positioning of the chest drainage is always indicated in cases of empyema $(\mathrm{pH}<7.2$, glucose $<40 \mathrm{mg} / \mathrm{dl}, \mathrm{LDH}>1000 \mathrm{U} / \mathrm{dl}$ ) and hemothorax. In malignant pleural effusions small bore chest tubes followed by pleurodesis are preferable to recurrent aspiration. After unsuccessful attempts to pleurodesis, drainage may be the only valid therapeutic approach for recurrent pleural effusions and chylothorax (Level of evidence: IV) (Grade C) [5, $7,8]$. Chest drainage is always required after thoracic surgery and thoracoscopy (Level of evidence: IV) (Grade C) [9].

The pleural symphysis is an absolute contraindication for thoracostomy through drainage, while bleeding disorders represent a relative contraindication. Possible complications include vagal-crisis, intercostal artery injury, lung injury, infection, re-expansion pulmonary oedema, malignant seeding in the site of drainage (Level of evidence: IV) (Grade C) [2, 3, 9].

The positioning of the chest drain needs the implementation of a small thoracotomy that is usually given in V-VI space on the mid-axillary line of the hemithorax or, in case of PNX, in II or III space on mid-clavicular line. The choice of the site for positioning the drainage tube can be made with greater accuracy under ultrasound guidance (Level of evidence: III) (Grade B) [9, 10].

The size of the drainage tube depends on the quantitative and qualitative characteristics of the fluid or air leaking to drain. In PNX it is possible to use a tube of small calibre $(14 \mathrm{ch})$; the size of the tube should be greater when the air leaking is important, the patient is unstable and requires mechanical ventilation, or in presence of blood loss. In parapneumonic or neoplastic effusions it is possible to use a tube of small calibre (14 ch), but, if the viscosity of the liquid becomes higher (pus or blood loss), it is necessary to place a tube with bigger calibre (Level of evidence: IV) (Grade C) [2, $3,5,9]$.

The chest drainage requires daily checks, in PNX the tube can be removed at the cessation of air leaking (at least 48 hours) and in the pleural effusions when the daily loss of fluid is less than 150 $\mathrm{mL}$ (Level of evidence: IV) (Grade C) [2, 3, 9].

\section{References}

1. Ernst A, Silvestri GA, Johnstone D. Interventional Pulmonology, Procedures. Guidelines from the American College of Chest Physicians. Chest 2003; 123: 1693-1717.

2. Baumann MH, Strange C, Heffner JE, et al. Management of spontaneous pneumothorax. An American College of Chest Physicians Delphi consensus statement. Chest 2001; 119: 590-602.

3. MacDuff A, Arnold T, Harvey J. Management of spontaneous pneumothorax: British Thoracic Society pleural disease guideline 2010. Thorax 2010; 65 (Suppl 2): ii18eii31.

4. Kelly AM, Kerr D, Clooney M. Outcomes of emergency department patients treated for primary spontaneous pneumothotax. Chest 2008; 134: 1033-1036.

5. Roberts ME, NevilleE, Berrisford RG, Antunes G, Ali NJ. Management of a malignant pleural effusion: British Thoracic Society pleural disease guideline 2010. Thorax 2010; 65 (Suppl 2): ii32eii40.

6. Tschopp LM. Rami-Porta R, Noppen M, Astoul P. Management of spontaneous pneumothorax: state of th art. Eur Respir J 2006; 28: 637-650.

7. Colice GL, Curtis A, Deslaurier B, et al. Medical and surgical treatment of parapneumonic effusions. An evidence-based guideline. Chest 2000; 118: 1158-1171. 
8. Mattioli S, Berrisford RG, Lugaresi ML, Aramini B. Survey on chest drainage system adopted in Europe. Interact CardioVasc Thorac Surg 2008; 7: 1155-1159.

9. Boutin C, Vialliat J, Aelony Y. Pratical thoracoscopy. Berlin: Springer Verlag; 1991.

10. Tzu-Hsiu Tsai, Pan-Chyr Yang. Ultrasound management of pleural disease. Curr Opin Pulm Med 2003; 9.

\section{Transthoracic fine needle aspiration}

The transthoracic fine needle aspiration (TTNA) is used in the diagnosis of lung cancer and lymphoma. TTNAs are performed on pulmonary nodules and masses, masses of the anterior and middle mediastinum, pleura and chest wall injury (Level of evidence: IIb) (Grade B) [1-7].

The TTNA has an almost absolute diagnostic accuracy where positive for malignancy, but, where negative, it may lead to wider margins of uncertainty (high sensitivity with low negative predictive value). Used in the second instance, following bronchoscopy (biopsies, transbronchial fine needle aspiration and transbronchial biopsy), which alone leads to the diagnosis in the $75.4 \%$ of cases, TTNA contributes to cytological diagnosis in $95.2 \%$ of cases. The diagnostic accuracy increases to $100 \%$ by associating repeated TTNAs with the clinical observation and TC studies (Level of evidence: IIb) (Grade B) [3, 4, 8].

TTNA contraindications are related to the need to avoid potentially severe complications: pneumothorax and bleeding. The most critical factors that increase risks and require a more careful assessment of the methodology are: the inability of patients to collaborate on the TTNA execution, the mechanical ventilation, the results of pneumonectomy, the bleeding disorder, thrombocytopenia, severe chronic obstructive pulmonary disease and the presence of unavoidable lung bubbles (Level of evidenceIV) (Grade C) [9].

The method performed under fluoroscopic guidance enhances the speed of execution and allows a direct view of the needle insertion with mild sensitivity in the determination of injury, the vascular structures and the bubbles. The TC guide requires a longer execution time but is currently used more frequently because it allows fine needle aspiration in parenchymal lesions, hilar and mediastinal, also of small dimension, by avoiding bubbles and vascular structures (Level of evidence: $I V$ ) (Grade C) [10-12].

Ultrasonography can guide the TTNA pleural lesions, peripheral parenchymal and mediastinal masses with the advantage of rapid execution, low cost, no radiation, real-time viewing, chance of avoiding necrotic areas, but this method is limited to injuries that produce an acoustic window (masse peripheral or mediastinal lesions) (Level of evidence: III) (Grade B) [13].

The possibility of obtaining an immediate evaluation of cytopathologists reduces the number of inadequate samples and increases the diagnostic sensitivity, negative predictive value and accuracy of the procedure (Level of evidence: III) (Grade B) $[14,15]$.
A large clinical documentation (years 19802000) on TTNA with different forms of guidance, needle localisation of lesions, presence of cytopathologists during the exam, the prevalence of malignancy in the population studied, showed a diagnostic sensitivity between $72 \%$ and $100 \%$, a specificity between $91 \%$ and $100 \%$, positive predictive value between $95 \%$ and $100 \%$ with a negative predictive value between $48 \%$ and $98 \%$. The negative predictive value and percentage of specific benign diagnosis is relatively low in this extensive case studies and this justifies the following use of TTNA with sharp needle (Level of evidence: IIb) (Grade B) [3, 4, 11, 13, 14, 15-18].

TTNA's common complications are PNX (between 2 and $56 \%$ of cases) and bleeding (5\% of cases) while vaso-vagal reactions, torsion of the lung, gas embolism, implantation of tumour cells along the needle circuit, cardiac tamponade, aspiration of cyst echinococcus are rare. Bleeding and gas embolism can be fatal. The PNX is undoubtedly the most common complication, it usually appears within the first hour of the TTNA execution and the approach is conservative; the positioning of the chest drainage is described in the $0 \%$ and $18 \%$ of the case studies. The presence of COPD, small injuries or deep lesions located in the lung parenchyma as the use of a needle with larger calibre or more steps seem to increase the risk of PNX complications. The bleeds are the second most common complication of TTNA, are usually selflimiting but can lead to death (Level of evidence: III) (Grade C) [3, 4, 15, 16, 19-25].

\section{References}

1. Protopas Z, Westcott JL. Transthoracic needle biopsy of mediastinal lymph nodes for staging lung and other cancer. Radiology 1996; 199: 489-496.

2. Ben-Yeuda D, Pollack A, Okon E, et al. Image guided core-needle biopsy in malignant lymphoma: Experince with 100 patients that suggests the technique is reliable. J Clin Oncol 1996; 14: 2431-2434.

3. Gasparini S, Ferretti M, Bicchi Secchi E, et al. Integration of transbronchial and percutaneous approch in the diagnosis of peripheral pulmonary nodules or masse. Chest 1995; 108: 1, 131-137.

4. Welker JA, Alattar M, Gautman S. Repeated needle biopsies combined with clinical observation are safe and accurate in the management of a solitary pulmonary nodule. Cancer 2005; 103, 3: 599-607.

5. Belfiore G, Camera L, Moggio G, et al. Middle mediastinum lesions: Preliminary experience with $\mathrm{CT}$ guided fine needle aspiration biopsy with a suprasternal approach. Radiology 1997; 202: 870-873.

6. Herman SJ, Holub RV, Weisbroa GL, et al. Anterior mediastinal masses: Utility of transthoracic needle biopsy. Radiology 1991; 180: 167-170.

7. Scott EM, Marshall TJ, Flower CDR, et al. Diffuse pleural thickening: Percutaneous CT-Guided cutting needle biopsy. Radiology 1995; 194: 867-870.

8. Gould MK, Fletcher J, Iannettoni MD, et al. Evaluation of patients with pulmonary nodules: when is it lung cancer? ACCP Evidence-Based Clinical Practice Guidelines (2nd Edition); Chest 2007; 132 (suppl 3): 108S-130S.

9. Nordestrom B. Transthoracic needle biopsy. $N$ Engl J Med 1967; 276: 1081-1082. 
10. Fink I, Gamsu H, Harter LP. CT-guided aspiration biopsy of the thorax. J Comput Assist Tomogr 1982; 10, 6: 958-962.

11. Yankelevitz DF, Ilenschke CI, Koizumi JII, et al. CTguided transthoracic needle of small solitary pulmonary nodules. Clin Imaging 1997; 21: 107-110.

12. Katada K, Kato R, Anno H, et al. Guidance with realtime CT fluoroscopy: Early clinical experience. Radiology 1996; 200: 851-856.

13. Rubens DJ, Strang JG, Fultz PJ, et al. Sonographic guidance of mediastinal biopsy: An effective alternative to CT guidance. Am J Roentgenol 1997; 169: 1605-1610.

14. Staroselski AN, Schwarz Y, Man A, et al. Additional information from percutaneous cutting needle biopsy following fine needle aspiration in the diagnosis of chest lesions. Chest 1998; 113: 1522-1525.

15. Santambrogio L, Nosotti M, Bellaviti N, et al. CT-guided fineneedle aspiration of solitary pulmonary nodules: A prospective randomized study of immediate cytologic evaluation. Chest 1997; 112: 423-425.

16. Khouri NF, Stitk FP, Erozan YS, et al. Transthoracic needle aspiration biopsy of benign and malignant lung lesions. Am J Roentgenol 1985; 144: 281-288.

17. Veale D, Gilemartin JJ, Sumerling MD, et al. Prospective evaluation of fine needle aspiration in the diagnosis of lung cancer. Thorax 1988; 43: 540-544.

18. Swischuk JL, Castandeda F, Patell JC, et al. Percutaneous transthoracic needle biopsy of the lung: review of 612 lesions. J Vasc Inter Radiol 1998; 9: 347-352.

19. FogarthyJP, Dudek G. An unusual case of lung torsion. Chest 1995; 108: 575-578

20. Aberle DR, Gamsu G, Golden JA, et al. Fatal systemic arterial air embolism following lung needle aspiration. Radiology 1987; 165: 351-353.

21. Berger RL, Dargan EL, Huang BL, et al. Dissemination of cancer cells by needle biopsy of the lung. J Thorac Cardiovasc Surg 1972; 63: 430-432.

22. Man A, Schwarz Y, Greif J. Case report: Cardiac tamponade following fine needle aspiration (FNA) of a mediastinal mass. Clin Radiol 1998; 63: 151-152.

23. McCorkell SJ. Unintended percutaneous aspiration of pulmonary echinococcal cystis. Am J Roentgenol 1984; 143: 123-126.

24. Milner LB, Ryan K, Gulla J. Fatal intrathoracic hemorrage after percutaneous aspiration lung biopsy. Am J Roentgenol 1979; 132: 280-281.

25. Berquist TH98, Bailey PB, Cortese DA, et al. Accuracy and complications in relation to location and type of lesion. Mayo Clin Proc 1980; 55: 475-481.

\section{Radiofrequency ablation}

Radiofrequency ablation (RFA) is a technique, used in humans since 2000 , for the palliative treatment of primary or secondary malignant pulmonary lesions which are unable to be healed by medical or surgical therapy. The RFA uses a sinusoidal current of frequency between 400 and $500 \mathrm{kHz}$ that, applied to the lesion using a needle-electrode through percutaneous fixture, mobilizes the ions of the tissues submitted to its action causing heat. The goal of the treatment is to obtain a thermo coagulation with permanent injury of the tissue near the electrode. After RFA treatment, a survival rate has been reported as follows: at 1,2, 3, 4 and 5 years of $78 \%, 57 \%, 36 \%$, $27 \%$ in patients who cannot have surgical indications; $27 \%$ in NSCLC patients with stage 1 and $87 \%, 78 \%, 57 \%, 57 \%$ and $57 \%$ in patients with pulmonary metastases of colorectal NPL. These sur- vival rates results are more satisfying than those obtained with radiotherapy alone. The efficacy of treatment with RFA is higher with nodules smaller than $3 \mathrm{~cm}$ (irrespective of histological type), keeping the maximum healable size to $5 \mathrm{~cm}$. The indication for RFA may be extended to the treatment of multiple pulmonary lesions (cut off indicative of 5) by repeated needle's placements if unilateral whether more sessions if bilateral. In a recent study, CT imaging-bronchoscopy-guided, internally cooled RFA results may be a potential therapeutic tool for local control in medically inoperable patients with stage I NSCLC (Level of evidence: IV) (Grade C) [1-9].

The most common complications of the RFA are represented by pain, cough and dyspnoea $(76 \%$ of cases) followed by the onset of PNX (28$42.3 \%$ ) which may occur later or become recurrent. Cases of sepsis, interstitial pneumonia and pleurisy have been decrypted after RFA. The FDA in December 2007 and September 2008, have reported deaths from complications arising after RFA treatment in patients with lung cancer so it is recommended to pay extreme attention to indications, selection of patients, modalities of treatment, and management of postoperative complications. Furthermore it have been reported that the RFA ablation devices have not been specifically approved for lung tumour ablation (Level of evidence: IV) (Grade C) [8, 10-13]

For the implementation of RFA, after CT-centring of the lesion a needle-electrode monopole, simple or coaxial, is positioned, connected to a device that delivers sinusoidal current. Unilateral multiple lesions may require one or more sessions of treatment. Bilateral lesions always require different sessions. Lesions larger than $3 \mathrm{~cm}$ require double needle's placement for a complete treatment. The RFA can be performed under local or general anaesthesia and ventilation with single or double lumen intubations depending on the site of the lesion and the patient's characteristics. During the CT-control after RFA it is observed the cockade aspect of the lesion with peripheral hyperaemia (framework for ground-glass), and moderate pleural effusion whether controls following 30 days from the operation and subsequent observed gradual loss of density until the formation of hyper dense scar tissue on the lesion core surrounded by a ring of hyper dense tissue (Level of evidence: $I V$ ) (Grade C) [2, 6, 7, 13].

\section{References}

1. Solbiati L, Goldberg N, Ierace T, et al. Hepatic metastases: Percutaneous radio-frequency ablation with cooled tip electrodes. Radiology 1997; 205: 367-373.

2. Dupuy DE, Zagoria RJ, Akerley W, Mayo-Smith WW, Kavanagh PV, Safran H. Percutaneous radiofrequency ablation of malignancies in the lung. Am J Roentgenol 2000; 174: 57-9.

3. Lee J, Lee Y, Kim I, Kim C. Percutaneous radiofrequency ablation for inoperable non-small cell lung cancer: A preliminary report. (American Roentgen Ray Society Meeting). Am J Roentgenol 2001; 176 (3 Suppl): 6. 
4. Barclay L. Radiofrequency ablation promising for unresectable lung neoplasm. J Vasc Ther Radiol 2004; 15: 463-470.

5. Simon JC, Dupuy DE, DiPietrillo TA, et al. Pulmonary radiofrequency ablation: long-term safety and efficacy in 153 patients. Radiology 2007; 243: 268-275.

6. Hiran C Fernando, MD. Radiofrequency Ablation to Treat Non-Small Cell Lung Cancer and Pulmonary Metastases. Supplement: The Minimally Invasive Thoracic Surgery Summit. Ann Thorac Surg 2008; 85: S780-S784.

7. Dupuy ED, Di Petrillo T, Gandhi S, et al. Radiofrequency ablation followed by conventional radiotherapy for medically inoperable stage I mon-small cell lung cancer. Chest 2006; v129: 738-745

8. Gadaleta C, Mattioli V, Colucci G, et al. Radiofrequency ablation of 40 lung neoplasm: preliminary results. Am J Roentgenol 2004; 183: 361-368.
9. Tanabe T, Koizumi T, Tsushima K, et al. Comparative study of three different catheters for CT imaging-bronchoscopy-guided radiofrequency ablation as a potential and novel interventional therapy for lung cancer. Chest 2010; 137: 890-7.

10. Yoshimatsu R, Yamagami T, Terayama K, Matsumoto T, Miura H, Nishimura T. Delayed and recurrent pneumothorax after radiofrequency ablation of lung tumors. Chest 2009; 135: 1002-1009.

11. FDA Alert: RF Ablation Devices to treat lung tumors. Kirk A. December 16 $6^{\text {th }}, 2007$.

12. FDA Public Health Notification: Radiofrequency Ablation of Lung Tumors - Clarification of Regulatory Status. September 24, 2008.

13. Lee NL, Jin GY, Goldberg SN, et al. Percutaneous radiofrequency ablation for inoperable non-small cell lung cancer and metastases: preliminary report. Radiology 2004; 230: 125-134.

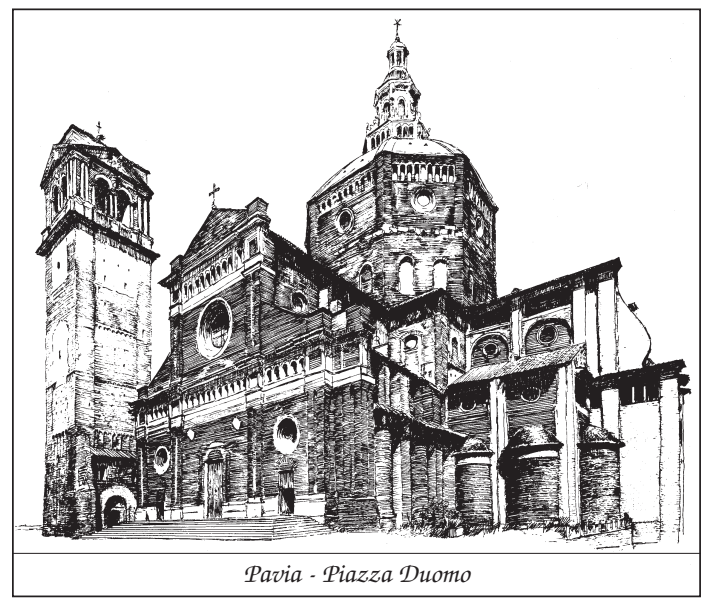

